\title{
EDITORIAL
}

\section{Integrating soft and hard infrastructures for inclusive development}

Welcome to the Journal of Infrastructure, Policy and Development (JIPD), a new kind of peerrefereed academic journal. This multi-disciplinary journal is dedicated to publishing articles of the highest quality on major aspects of infrastructure, policies and economic development. The three words in the journal's title, "infrastructure", "policy" and "development", are core to the vision of this journal.

With its broad scope covering infrastructure-related issues, a novel feature of this journal is that it covers the whole range of infrastructure, including both "hard" infrastructure and "soft" infrastructure. In addition, it discusses how institutional infrastructure may be applied to different physical infrastructure activities, with the support of effective government policy, to reach the ultimate aim of development. The target audiences of the journal are scientific researchers, professional practitioners, and policymakers from academia, industry and regulatory institutions.

Let me share with you some thoughts on the changing trends of infrastructure development.

Infrastructure development has always been critical to developing countries and developed economies. Infrastructure systems are important in maintaining and advancing economic growth, and paramount to global sustainability. From transport systems to communication lines, all facets of the economy are affected by the availability and reliability of its infrastructure systems.

We have witnessed that, since the end of World War II, infrastructure has progressed significantly and contributed positively to development. However, the quantity and quality of the world's infrastructure in general has been lower than what is actually required. Weak infrastructure has become a "constraint" in the future development of most regions. One notable challenge is the lack of infrastructure finance. Infrastructure requires significant investment that not many countries can afford. As infrastructure is usually considered a public good, the responsibility for its provision rests on the public sector. Unfortunately, government revenues are severely limited in most countries; this leaves open an avenue for forging solutions with private enterprises, not only for financial support but also for technical management and operational expertise for large-scale projects. However, to ensure the successful implementation of public-private partnerships (PPP), other complementary institutions become necessary pre-conditions. For example, good governance plays an integral role in the delivery of PPP infrastructure projects. A sound legal system also plays a critical role in mitigating risks and fostering a climate conducive for attracting private infrastructure investment. In this regard, it has been noted that weak institutional regimes and poor public governance make infrastructure projects less attractive to secure private sector financing.

In addition, there are also problems with maximizing the usage of existing infrastructure systems. We can observe that some infrastructure projects are functioning poorly and thus do not realize their development objective of helping the poor in alleviating poverty and attaining socially inclusive development. This under-utilization may be partly due to the absence of a supporting environment for physical infrastructure, such as legal and regulatory frameworks, institutions and good policies. 
This is because physical infrastructure systems are intrinsically related to the institutions that directly regulate the maintenance and expansion of services provided by infrastructure. Hence, the failures of soft infrastructure effectively reduce the macroeconomic impact of an infrastructure project. In fact, effective legal and regulatory frameworks, together with favourable policies — which collectively represent soft infrastructure - play an equally integral role in complementing physical, or hard, infrastructure by laying the foundations for the efficient functioning of infrastructure systems.

To date, considerable research and policy studies have been conducted to examine the link between the physical infrastructure development and economic growth. Yet, there is a paucity of academic literature that critically examines the role of soft infrastructure. The nexus between soft infrastructure and hard infrastructure is still not clear. A more in-depth investigation of their complementary roles is needed due to their increasing importance. This journal provides a platform on which we can examine the nexus between the roles of soft infrastructure and hard infrastructure in order to foster a wider understanding of their challenges and develop a roadmap to addressing these challenges.

To accomplish this, this journal seeks to provide sound solutions to key questions on the roadmap, for instance: to what extent can soft infrastructure components promote infrastructure development. What is the role of policy in the development and functioning of infrastructure systems? How does one achieve effective governance - a vital component of soft infrastructure - that is grounded in the rule of law, that is accountable, participatory, predictable and transparent? How is good economic governance necessary to ensure collective action, the reduction of transaction cost, the enforcement of contracts, and the security of property rights in the provision of infrastructure services? What kind of policy environment is critical in promoting infrastructure development? Recognizing that the private sector complements the public sector in responding to the market demand for the provision of certain infrastructure services, what kind of institutional and policy framework is necessary for attracting private investment in infrastructure? What kind of legal and regulatory system will offer protection for public and private enterprises in infrastructure development? How can policies, institutional arrangements, and governance facilitate the development of the infrastructure? In an era of economic globalization, how can international cooperation in global governance help to realize infrastructure connectivity across the national boundaries? Both mature and new, cutting-edge research underpinned by solid empirical or theoretical studies are welcomed by the journal.

From the brief discussions above, we can see that we are in a new era of regenerating the development of infrastructure to meet new challenges in this rapidly changing world. We should continue our past efforts in infrastructure development, but in a more comprehensive manner by combining both hard and soft infrastructure with government policy to achieve long-lasting prosperity and welfare for mankind. Our journal will provide a reliable platform to encourage discussion and analyses of the relevant issues and concerns about infrastructure, as well as to promote dialogue in this area. In this spirit, the overarching goal of the journal is to establish itself as a credible source of information covering areas of hard and soft infrastructure, along with other related policies and economic development matters.

In the journal, there are currently four types of sub-divisions: Original Articles, which publishes results of original research; Policy Dialogue, which highlights policy conversations with an 
experienced practitioner or thinker who will present their perspectives on important topics of research, policy, or practice; Policy Insights, to present singular discoveries or assessments that suggest new directions or clarify ideas, whether on theory, concepts, methods, or practice; and Case Studies or Book Reviews.

Launching a new journal is a mission impossible without collaboration. I would like to extend my sincere thanks to the authors, reviewers and colleagues of our editorial team. In particular, my greatest thanks go to the reputable Advisory Board of the journal, chaired by Professor Justin Yifu Lin, for their guidance, as well as the Editorial Board, which consists of leading academics from top institutions across the world. Last but not least, I would like to thank EnPress, the publishers of this journal.

Happy reading! Let us enrich our understanding of the world of infrastructure together.

Editor-in-Chief

Qingyang Gu 